\title{
Suscetibilidade de linhagens de frangos de corte à síndrome ascítica
}

\author{
Manoel Garcia Neto ${ }^{(1)}$ e Egladson João Campos ${ }^{(2)}$
}

\begin{abstract}
(1)Universidade Estadual Paulista, Dep. de Apoio, Produção e Saúde Animal, Caixa Postal 533, CEP 16050-680 Araçatuba, SP. E-mail: mgarcia@fmva.unesp.br (2)Universidade Federal de Minas Gerais, Escola de Veterinária, Caixa Postal 567, CEP $30123-970$ Belo Horizonte, MG. E-mail: metta@prover.com.br
\end{abstract}

\begin{abstract}
Resumo - O objetivo deste trabalho foi estudar a suscetibilidade à síndrome ascítica de machos e fêmeas em linhagens comerciais de frango de corte. Todas as aves receberam ração ad libitum com 3.050 kcal/ME. Foram comparadas as linhagens comerciais representadas pela Cobb, Hubbard e Ross, machos e fêmeas. O delineamento utilizado foi o inteiramente casualizado, em esquema fatorial. As aves foram aleatoriamente alojadas em um galpão experimental de $8 \times 76 \mathrm{~m}$, com 18 boxes de 3x3,5 m cada e 100 aves por divisão, num total de 1.800 aves. Os resultados revelaram que a incidência de ascite independe da linhagem comercial dos frangos de corte, entretanto, os machos foram mais suscetíveis.
\end{abstract}

Termos para indexação: distúrbio metabólico, aspectos nutricionais, nutrição animal.

\section{Ascites syndrome effects in different commercial broilers}

\begin{abstract}
The objective of this work was to verify the incidence of ascites in males and females on commercial lines of broilers. All birds received ration ad libitum with 3,050 kcal/ME. The commercial lines Cobb, Hubbard and Ross, males and females, were compared. A factorial design was used with three replications per treatment. A total of 1,800 birds were housed at random in an experimental shed of $8 \times 76 \mathrm{~m}$, with 18 compartments of $3 \times 3.5 \mathrm{~m}$ each and 100 birds per division. The results showed that the incidence of ascites was independent of the commercial broiler line, however, males were more susceptible.
\end{abstract}

Index terms: metabolic disorder, nutritional effects, animal nutrition.

\section{Introdução}

A exploração avícola, em virtude de mudanças tecnológicas das últimas décadas, proporcionou uma ave altamente transformadora de alimento, explorada de uma maneira intensiva e avaliada pela relação peso $/ \mathrm{m}^{2} \mathrm{ou}$ aves $/ \mathrm{m}^{2}$. Para que o frango de corte moderno possa manifestar seu potencial genético, há necessidade do fornecimento de rações bem balanceadas, ambiente saudável, além do oferecimento de água, espaços adequados de comedouros e bebedouros, proporcionando, assim, um bom manejo (Back, 1991).

A fim de atender a características genéticas relacionadas à maior eficiência de produção, o suprimento das exigências nutricionais torna-se cada vez mais importante. Deste modo, a interação genética x nutrição é muito relevante no surgimento de doenças metabólicas (Lopez Coello et al., 1991).

Entre os problemas metabólicos atuais, a síndrome ascítica, face à sua própria etiologia, tem se mostrado de difícil controle. O termo genérico ascite se refere a uma síndrome de múltiplas origens, caracterizada em seu quadro final pelo acúmulo de fluído na cavidade abdominal (Lopez Coello et al., 1991). Assim, as aves que morrem em decorrência desta síndrome exibem uma distensão da região abdominal típica, conhecida pelos avicultores como barriga d'água. Um dos primeiros relatos sobre ascite foi feito por Scrivner (1946), como sendo uma condição clínica conhecida por edema, gota visceral, barriga d'água, entre outros nomes, que se caracterizava por acúmulo de líquido amarelo-claro na cavidade abdominal, culminando com a morte da ave.

A síndrome ascítica, no Brasil, foi constatada de forma discreta, a partir de 1980 (Amorim Filho, 1989; Back, 1991) e somente em 1983 foi criado um item específico para ascite no quadro de condenações da Inspeção Federal (Amorim Filho, 1989).

As perdas econômicas causadas pela síndrome ascítica têm se mostrado crescentes em vários países, (Bottje et al., 1997). No Brasil, Back (1991) constatou que o porcentual de condenação por ascite, em relação ao total de condenação, passou de 10,4\% em 1987 para 
27,4\% em 1990, e, segundo esse autor, a síndrome ascítica é atualmente uma das principais, senão a principal causa de condenação de frangos no país.

O objetivo deste trabalho foi estudar a suscetibilidade de machos e fêmeas à síndrome ascítica em linhagens comerciais de frangos de corte.

\section{Material e Métodos}

O experimento foi realizado na Empresa Agro Avícola Predileto Ltda., situada no Município de Amparo, SP, numa altitude de $658 \mathrm{~m}$. As temperaturas máximas, médias e mínimas registradas foram, respectivamente, $31,5^{\circ} \mathrm{C}, 21,6^{\circ} \mathrm{C}$ e $9,0^{\circ} \mathrm{C}$.

Utilizou-se um galpão de alvenaria de 76x8 m com tela nas laterais, com sistema de cortinas, e piso de concreto, pé-direito de $2,80 \mathrm{~m}$, coberto com telhas francesas, possuindo corredor central, dividido em 48 compartimentos de 3,0x3,5 m cada, com capacidade individual para cem aves. O material utilizado como cama foi maravalhas.

Nos dois primeiros dias, foram utilizados dois bebedouros de pressão do tipo copo com capacidade para dois litros de água cada um, e um comedouro do tipo bandeja de 0,3 $00,4 \mathrm{~m}$ em cada compartimento. No terceiro dia incorporou-se um bebedouro pendular, o qual ficava suspenso durante a noite, e no quinto dia após o alojamento das aves, foram colocados três comedouros tubulares com capacidade para $20 \mathrm{~kg}$ de ração cada. No sétimo dia foram retirados os bebedouros de pressão do tipo copo e no décimo quarto dia, os comedouros do tipo bandeja. Como fonte de aquecimento, foram utilizados aquecedores (campânulas) a gás, em cada compartimento, durante os primeiros dez dias de vida das aves.

O delineamento utilizado foi o inteiramente casualizado, em esquema fatorial com seis tratamentos, constituídos pela combinação de três linhagens comerciais de frangos de corte, Cobb, Hubbard e Ross, machos e fêmeas, com três repetições de cem aves cada.

Foram utilizadas 1.800 aves, sendo 600 aves de cada linhagem comercial, 300 machos e 300 fêmeas, sexadas, distribuídas em 18 boxes dos 48 disponíveis. A ração utilizada foi uma inicial para frangos de corte, farelada, com alto nível energético (Tabela 1). O arraçoamento foi feito à vontade a partir de um dia até o término do experimento, ou seja, aos 39 dias de idade. Ao final de cada semana, as seguintes variáveis foram avaliadas: peso médio corporal, consumo de ração, conversão alimentar e taxa de mortalidade.

Todas as aves que morreram durante o período experimental foram necropsiadas, sendo diagnosticada síndrome ascítica quando as aves apresentavam líquido ascítico na cavidade abdominal e congestão generalizada (cianoses), além de lesões pré-ascíticas como dilatação ventricular direita, hidropericárdio e congestão vascular (Bottje et al., 1997).

Durante a necropsia, considerou-se um coração normal aquele apresentando forma cônica, firme e especialmente sem evidência de flacidez ventricular direita. Quanto ao fígado, considerou-se normal aquele com tamanho e cor característica, com bordas agudas e bem definidas (Teuscher et al., 1971). Durante a necropsia foram ainda observadas e identificadas as aves com evidências de edema e congestão visceral.

Os demais órgãos, principalmente pulmões, não foram considerados como um parâmetro de avaliação, em virtude das recomendações afirmarem que, para esta finalidade, as aves deveriam ser necropsiadas, nos pri-

Tabela 1. Componentes e composição calculada da ração utilizada no experimento.

\begin{tabular}{lr}
\hline Componentes & Quantidade \\
\hline Milho (\%) & 62,43 \\
Farelo de soja (\%) & 24,17 \\
Farinha de carne e ossos (\%) & 4,68 \\
Protenose (\%) & 3,00 \\
Farinha de peixe (\%) & 2,00 \\
Óleo bruto de soja (\%) & 1,27 \\
Gordura de frango (\%) & 1,00 \\
Suplemento vitamínico mineral ${ }^{(1)}(\%)$ & 0,50 \\
Calcário calcítico (\%) & 0,45 \\
Sal (\%) & 0,30 \\
DL-metionina (\%) & 0,20 \\
\hline Total & 100,00 \\
\hline Composição calculada & 21,00 \\
Proteína bruta (\%) & $3.050,00$ \\
Energia metabolizável (kcal/kg) & 1,20 \\
Cálcio (\%) & 0,71 \\
Fósforo (\%) & 0,52 \\
Metionina (\%) & 0,84 \\
Metionina + cistina (\%) & 1,04 \\
Lisina (\%) & \\
(1)Suplementação por quilo de ração: vitamina A, 12.000 UI; vitamina \\
D3, 2.500 UI; vitamina E, 15 mg; vitamina K, 1,5 mg; tiamina, 1,0 mg; \\
riboflavina, 2,0 mg; pantotenato de cálcio, 6,0 mg; niacina, 25,0 mg; \\
piridoxina, 4,0 mg; biotina, 50,0 $\mu$ g; colina, 125,0 mg; ácido fólico, \\
0,73 mg; vitamina B12, 10,0 $\mu \mathrm{g} ;$ antioxidante, 125,0 mg; coccidiostato, \\
125,0 mg; Cu, 4,0 mg; I, 0,3 mg; Mn, 27,0 mg; Zn, 20,0 mg; Fe, \\
23,0 mg; Se, 0,13 mg.
\end{tabular}


meiros cinco minutos após o sacrifício (Lopez Coello et al., 1991).

Os dados foram submetidos à analise de variância e as médias comparadas pelo teste de Duncan a $5 \%$ de probabilidade.

\section{Resultados e Discussão}

Não houve interação significativa entre linhagem e sexo em nenhuma das características estudadas.

As aves da linhagem Hubbard apresentaram maior consumo de ração desde a primeira semana (Tabela 2). O maior consumo de ração pelos machos tornou-se significativo a partir da quarta semana. Em relação ao consumo total médio, os machos consumiram significativamente cerca de $8 \%$ a mais de ração, em relação às fêmeas.
As aves da linhagem Cobb, cujo peso inicial de pintinhos for maior, não mantiveram diferença favorável inicial (Tabela 2). Desta forma, o peso na época do alojamento não influenciou os pesos subseqüentes, e, ao término do experimento, a linhagem Cobb apresentou o menor peso. As aves das outras duas linhagens não apresentaram diferenças significativas em seus pesos médios durante o período experimental, com exceção da primeira semana. Estes dados confirmam que o peso corporal às duas semanas é um bom indicador do potencial genético para rápido crescimento (Dale \& Villacres, 1988), e não o peso dos pintinhos na época do alojamento.

Não houve diferenças significativas entre os pesos de machos e fêmeas nas três primeiras semanas, entretanto, a partir da quarta semana, foi verificado maior peso nos machos, o qual se manteve até o final do experimento (39 dias), e correspondeu a uma diferença em

Tabela 2. Consumo, peso e ganho de peso acumulados e conversão alimentar, segundo a linhagem e o sexo de frangos de corte, avaliados ao final de cada semana ${ }^{(1)}$.

\begin{tabular}{|c|c|c|c|c|c|c|}
\hline \multirow[t]{2}{*}{ Linhagem e sexo } & \multicolumn{6}{|c|}{ Semana } \\
\hline & 1 & 2 & 3 & 4 & 5 & 6 \\
\hline & \multicolumn{6}{|c|}{ Consumo (g) } \\
\hline Cobb & $75,16 b$ & $308,44 b$ & $710,89 \mathrm{c}$ & $1.325,09 \mathrm{~b}$ & $2.125,62 \mathrm{c}$ & $2.654,76 b$ \\
\hline Ross & $89,32 \mathrm{a}$ & $335,37 \mathrm{a}$ & $748,57 b$ & $1.369,17 b$ & $2.200,04 b$ & $2.726,20 \mathrm{~b}$ \\
\hline Hubbard & $92,90 \mathrm{a}$ & $348,94 a$ & $792,02 \mathrm{a}$ & $1.452,78 \mathrm{a}$ & $2.292,90 \mathrm{a}$ & $2.845,33 \mathrm{a}$ \\
\hline Macho & $86,64 a$ & $333,06 a$ & $763,30 a$ & $1.419,82 \mathrm{a}$ & $2.281,52 \mathrm{a}$ & $2.854,14 \mathrm{a}$ \\
\hline Fêmea & $84,94 \mathrm{a}$ & $328,77 \mathrm{a}$ & $737,68 \mathrm{a}$ & $1.344,87 \mathrm{~b}$ & $2.130,85 b$ & $2.630,06 \mathrm{~b}$ \\
\hline \multirow[t]{2}{*}{$\mathrm{CV}(\%)$} & 4,91 & 4,85 & 3,63 & 3,12 & 2,61 & 2,83 \\
\hline & \multicolumn{6}{|c|}{ Peso $(\mathrm{g})^{(2)}$} \\
\hline Cobb & $87,99 \mathrm{c}$ & $192,86 b$ & $418,15 b$ & $756,67 b$ & $1.174,28 b$ & $1.405,73 b$ \\
\hline Ross & $98,36 b$ & $223,58 a$ & $470,79 a$ & $834,72 a$ & $1.271,85 \mathrm{a}$ & $1.483,77 \mathrm{a}$ \\
\hline Hubbard & $105,73 \mathrm{a}$ & $239,78 \mathrm{a}$ & $492,89 a$ & $850,83 \mathrm{a}$ & $1.270,06 \mathrm{a}$ & $1.514,29 \mathrm{a}$ \\
\hline Macho & $97,10 \mathrm{a}$ & $219,52 a$ & $469,43 a$ & $841,91 \mathrm{a}$ & $1.299,86 \mathrm{a}$ & $1.544,31 \mathrm{a}$ \\
\hline Fêmea & $97,62 \mathrm{a}$ & $217,97 \mathrm{a}$ & $451,78 \mathrm{a}$ & $786,24 b$ & $1.177,60 \mathrm{~b}$ & $1.391,55 b$ \\
\hline \multirow[t]{2}{*}{$\mathrm{CV}(\%)$} & 5,11 & 6,12 & 3,86 & 2,89 & 2,78 & 2,99 \\
\hline & \multicolumn{6}{|c|}{ Ganho de peso $(\mathrm{g})$} \\
\hline Cobb & $38,75 \mathrm{c}$ & $143,62 \mathrm{c}$ & $368,90 \mathrm{c}$ & $707,42 b$ & $1.125,03 b$ & $1.356,48 b$ \\
\hline Ross & $51,65 b$ & $176,86 b$ & $424,07 b$ & $788,00 \mathrm{a}$ & $1.225,14 \mathrm{a}$ & $1.437,05 \mathrm{a}$ \\
\hline Hubbard & $59,73 \mathrm{a}$ & $193,78 \mathrm{a}$ & $446,89 a$ & $804,83 a$ & $1.224,06 \mathrm{a}$ & $1.468,29 \mathrm{a}$ \\
\hline Macho & $49,51 \mathrm{a}$ & $171,93 a$ & $421,85 \mathrm{a}$ & $794,32 \mathrm{a}$ & $1.252,27 \mathrm{a}$ & $1.496,72 \mathrm{a}$ \\
\hline Fêmea & $50,57 \mathrm{a}$ & $170,91 \mathrm{a}$ & $404,73 \mathrm{a}$ & $739,18 b$ & $1.130,55 \mathrm{~b}$ & $1.344,49 \mathrm{~b}$ \\
\hline \multirow[t]{2}{*}{$\mathrm{CV}(\%)$} & 10,00 & 7,71 & 4,22 & 3,03 & 2,87 & 3,09 \\
\hline & \multicolumn{6}{|c|}{ Conversão alimentar (g consumo/g ganho) } \\
\hline Cobb & $1,95 \mathrm{a}$ & $2,15 \mathrm{a}$ & $1,93 a$ & $1,87 \mathrm{a}$ & $1,89 \mathrm{a}$ & $1,96 \mathrm{a}$ \\
\hline Ross & $1,75 b$ & $1,91 \mathrm{~b}$ & $1,77 \mathrm{~b}$ & $1,74 \mathrm{c}$ & $1,80 \mathrm{~b}$ & $1,90 \mathrm{~b}$ \\
\hline Hubbard & $1,56 \mathrm{c}$ & $1,81 \mathrm{~b}$ & $1,77 \mathrm{~b}$ & $1,81 \mathrm{~b}$ & $1,88 \mathrm{a}$ & $1,94 \mathrm{a}$ \\
\hline Macho & $1,79 a$ & $1,97 \mathrm{a}$ & $1,82 \mathrm{a}$ & $1,79 b$ & $1,82 b$ & $1,91 \mathrm{~b}$ \\
\hline Fêmea & $1,72 \mathrm{a}$ & $1,94 \mathrm{a}$ & $1,83 \mathrm{a}$ & $1,82 \mathrm{a}$ & $1,89 \mathrm{a}$ & $1,96 \mathrm{a}$ \\
\hline $\mathrm{CV}(\%)$ & 8,00 & 5,77 & 0,96 & 1,23 & 1,89 & 1,68 \\
\hline
\end{tabular}

(1)Para cada variável e para cada coluna, médias seguidas da mesma letra não diferem entre si a 5\% de probabilidade, pelo teste de Duncan. ${ }^{(2)}$ Peso das aves com um dia: 49,25a (Cobb), 46,72b (Ross) e 46,00b (Hubbard); 47,59a (machos) e 47,05a (fêmeas). 
torno de $10 \%$ no peso final. Estes dados concordam com os de Harms (1969), Campos et al. (1979) e Barbosa (1992), os quais afirmaram que, devido ao maior desenvolvimento, os machos tendem a alcançar um maior peso corporal.

As aves da linhagem Cobb apresentaram o menor ganho de peso (Tabela 2). Nas últimas três semanas, as aves das linhagens Hubbard e Ross igualaram os seus ganhos de peso, evidenciando que as diferenças nas curvas de crescimento devem-se a características genéticas. Diferenças no ganho de peso entre linhagens foram também observadas por Orr et al. (1984), Lovatto (1989) e Gonzales et al. (1998). Em relação ao sexo, a partir da quarta semana, houve um ganho de peso maior por parte dos machos em 10,2\%, em relação ao observado nas fêmeas. Estes dados confirmam a maior precocidade dos machos, os quais, na maioria das vezes apresentam um melhor ganho de peso em relação às fêmeas (Santos, 1977; Campos et al., 1979; Barbosa, 1992).

A conversão alimentar foi afetada significativamente pela linhagem, e os melhores resultados foram obtidos em aves da linhagem Ross (Tabela 2). Foram observadas diferenças significativas favoráveis aos machos em relação à conversão alimentar, a partir da quarta semana. A superioridade dos machos, tanto no ganho de peso como na conversão alimentar também foi constatada por Harms (1969), Campos et al. (1979) e Hulan et al. (1984).

Apenas durante a terceira e quarta semanas, foram verificadas diferenças significativas em relação à mortalidade; a linhagem Cobb apresentou os maiores índices nesse período (Tabela 3). Os machos apresentaram valores menores de mortalidade em relação às fêmeas, entre a segunda e quarta semana experimental. Todavia, na quinta e na sexta semanas, os valores verificados nos machos foram igualados estatisticamente aos das fêmeas. De acordo com Gehle et al. (1974) e Barbosa (1992), os machos se mostram mais propensos à mortalidade.

Nenhum caso de mortalidade por síndrome ascítica foi verificado até a terceira semana. Entretanto, a partir da quarta semana, e até o final do experimento, todas as linhagens apresentaram casos de síndrome ascítica, mas sem diferença estatística entre si (Tabela 3). Cueva et al. (1974) e Barbosa (1992) também constataram mortalidade por síndrome ascítica somente após a terceira semana de idade. Os machos demonstraram uma tendência maior para casos de síndrome ascítica, que ocorreu de forma significativa apenas na sexta semana. Na relação entre síndrome ascítica e a mortalidade total, os machos apresentaram 52,24\% a mais de mortalidade do que as fêmeas. Maior mortalidade por síndrome ascítica nos machos foi relatada também por Wideman

Tabela 3. Porcentuais de mortalidade e de mortalidade por síndrome ascítica acumulados, segundo a linhagem e o sexo de frangos de corte, avaliados ao final de cada semana ${ }^{(1)}$.

\begin{tabular}{|c|c|c|c|c|c|c|}
\hline \multirow[t]{2}{*}{ Linhagem e sexo } & \multicolumn{6}{|c|}{ Semana } \\
\hline & 1 & 2 & 3 & 4 & 5 & 6 \\
\hline & \multicolumn{6}{|c|}{ Mortalidade (\%) } \\
\hline Cobb & $0,83 \mathrm{a}$ & $3,17 \mathrm{a}$ & $4,19 \mathrm{a}$ & $5,23 \mathrm{a}$ & $7,17 \mathrm{a}$ & $12,96 \mathrm{a}$ \\
\hline Ross & $1,33 \mathrm{a}$ & $1,68 \mathrm{a}$ & $2,36 b$ & $3,39 b$ & $5,42 \mathrm{a}$ & $10,50 \mathrm{a}$ \\
\hline Hubbard & $0,67 \mathrm{a}$ & $1,17 \mathrm{a}$ & $3,02 \mathrm{ab}$ & $4,05 \mathrm{ab}$ & $5,79 \mathrm{a}$ & $13,96 \mathrm{a}$ \\
\hline Macho & $0,67 \mathrm{a}$ & $1,34 b$ & $2,36 b$ & $3,16 b$ & $5,92 \mathrm{a}$ & $13,86 a$ \\
\hline Fêmea & $1,22 \mathrm{a}$ & $2,67 \mathrm{a}$ & $4,02 \mathrm{a}$ & $5,29 \mathrm{a}$ & $6,34 \mathrm{a}$ & $11,09 \mathrm{a}$ \\
\hline $\mathrm{CV}(\%)$ & 83,04 & 49,89 & 27,69 & 21,53 & 16,16 & 20,75 \\
\hline & \multicolumn{6}{|c|}{ Mortalidade por síndrome ascítica $(\%)^{(2)}$} \\
\hline Cobb & 0,00 & 0,00 & 0,00 & $0,52 \mathrm{a}$ & $4,63 \mathrm{a}$ & $5,15 \mathrm{a}$ \\
\hline Ross & 0,00 & 0,00 & 0,00 & $0,52 \mathrm{a}$ & $4,31 \mathrm{a}$ & $4,83 \mathrm{a}$ \\
\hline Hubbard & 0,00 & 0,00 & 0,00 & $0,34 \mathrm{a}$ & $4,33 \mathrm{a}$ & $4,67 \mathrm{a}$ \\
\hline Macho & 0,00 & 0,00 & 0,00 & $0,46 a$ & $6,43 a$ & $6,89 \mathrm{a}$ \\
\hline Fêmea & 0,00 & 0,00 & 0,00 & $0,46 \mathrm{a}$ & $2,42 \mathrm{a}$ & $2,88 \mathrm{~b}$ \\
\hline $\mathrm{CV}(\%)$ & 0,00 & 0,00 & 0,00 & 48,03 & 39,30 & 27,37 \\
\hline
\end{tabular}

(1)Para cada variável e para cada coluna, médias seguidas da mesma letra não diferem entre si a $5 \%$ de probabilidade, pelo teste de Duncan. ${ }^{(2)}$ Síndrome ascítica/mortalidade geral (\%): 39,74a (Cobb), 46,00a (Ross) e 33,45a (Hubbard); 49,71a (machos) e 25,97b (fêmeas). 
Junior (1989) e Silva (1991). A maior ocorrência da síndrome ascítica dos machos em relação às fêmeas seria, segundo Soncini (1989), causada pela maior demanda de oxigênio requerida pelos machos.

A elevação de temperatura no último período experimental aumentou os casos de morte por síndrome ascítica (Figura 1). A maioria das mortes das aves, nesse período (Tabela 3), foi decorrente de lesões causadas pela síndrome ascítica, a qual, associada à elevação da temperatura, sobrecarregou ainda mais os pulmões, o coração e o fígado, favorecendo a alta mortalidade, por ultrapassar, segundo Lopez Coello et al. (1991), Macari et al. (1991) e Furlan (1992), os limites fisiológicos do sistema cárdio-pulmonar. As aves da linhagem comercial Hubbard que apresentaram maior velocidade de crescimento não revelaram maior propensão a morrer por síndrome ascítica (Tabela 2). Este resultado é contrá-

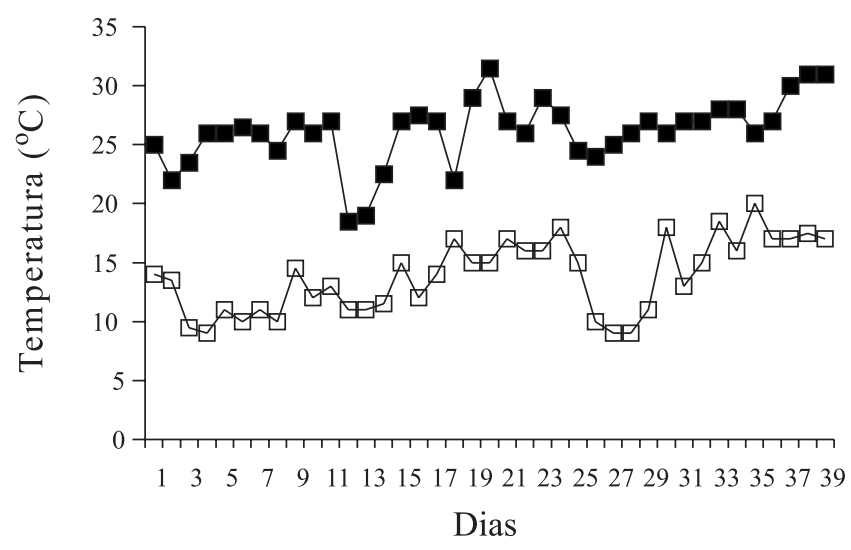

Figura 1. Temperaturas máximas ( $\square$ ) e mínimas $(\square)$ registradas no galpão durante o período experimental de 6 semanas. rio aos encontrados anteriormente, que afirmam que as linhagens mais precoces apresentam maior incidência de casos ascíticos (Lopez Coello \& Wideman Junior, 1986; Lopez Coello et al., 1991; Macari et al., 1991; Silva, 1991; Gonzales et al., 1998).

As lesões macroscópicas, constatadas durante a necropsia, não evidenciaram diferenças significativas em nenhum dos parâmetros analisados, ou seja, as aves das diferentes linhagens apresentaram resultados semelhantes quanto à presença de exsudato ascítico líquido, exsudato ascítico gelatinoso, deformações de coração e de fígado e congestão do trato digestivo (Tabela 4). Estes resultados concordam com os observados em relação à porcentagem de mortalidade por síndrome ascítica, isto é, não houve variação significativa entre as linhagens, quanto ao porcentual de aves que morreram por ascite.

Há um consenso sobre o fato de que o atual frango de corte, apresenta maior suscetibilidade à síndrome ascítica, por causa da sua maior precocidade (Silva, 1985; Julian et al., 1987; Lopez Coello et al., 1991). Esta informação foi confirmada neste trabalho, ou seja, os machos apresentaram significativamente maior incidência da síndrome, apresentando maior número de lesões cardíacas e hidropericárdio (Tabela 4). Além disso, apresentaram maior congestão no trato digestivo e maior porcentual de fluido ascítico gelatinoso do que as fêmeas. Estes resultados concordam com os de Lopez Coello et al. (1991) e Barbosa (1992). Entretanto, tanto machos como fêmeas apresentaram semelhantes porcentuais de líquido ascítico e lesões macroscópicas no fígado.

Tabela 4. Parâmetros de necropsia, segundo a linhagem e o sexo de frangos de corte ${ }^{(1)}$.

\begin{tabular}{|c|c|c|c|c|c|c|}
\hline \multirow[t]{3}{*}{ Linhagem e sexo } & \multicolumn{6}{|c|}{ Parâmetros de necropsia $(\%)^{(2)}$} \\
\hline & \multicolumn{2}{|c|}{ Exsudato ascítico } & \multirow{2}{*}{ Hidropericárdio } & \multicolumn{2}{|c|}{ Lesões } & \multirow{2}{*}{$\begin{array}{l}\text { Trato digestivo } \\
\text { congesto }\end{array}$} \\
\hline & Líquido & Gelatinoso & & Cardíacas & Hepáticas & \\
\hline Cobb & $14,22 \mathrm{a}$ & $26,73 a$ & $44,74 a$ & $45,63 \mathrm{a}$ & $36,46 \mathrm{a}$ & $7,36 \mathrm{a}$ \\
\hline Ross & $20,64 a$ & $27,86 a$ & $66,79 \mathrm{a}$ & $56,45 \mathrm{a}$ & $46,86 a$ & $19,53 \mathrm{a}$ \\
\hline Hubbard & $19,77 \mathrm{a}$ & $17,14 \mathrm{a}$ & $73,72 \mathrm{a}$ & $61,00 \mathrm{a}$ & $53,09 \mathrm{a}$ & $9,31 \mathrm{a}$ \\
\hline Macho & $22,95 a$ & $33,84 a$ & $73,10 \mathrm{a}$ & $68,89 \mathrm{a}$ & $52,95 \mathrm{a}$ & $16,60 \mathrm{a}$ \\
\hline Fêmea & $13,47 \mathrm{a}$ & $13,98 b$ & $50,40 \mathrm{~b}$ & $39,82 b$ & $37,99 \mathrm{a}$ & $7,53 b$ \\
\hline $\mathrm{CV}(\%)$ & 56,17 & 50,12 & 30,49 & 26,75 & 34,20 & 74,21 \\
\hline
\end{tabular}

${ }^{(1)}$ Para cada variável e para cada coluna, médias seguidas da mesma letra não diferem entre si a 5\% de probabilidade, pelo teste de Duncan. ${ }^{(2)}$ Total de aves necropsiadas: 74 (Cobb), 63 (Ross) e 81 (Hubbard); 120 (machos) e 98 (fêmeas). 


\section{Conclusão}

As diferentes linhagens apresentam o mesmo grau de suscetibilidade à síndrome ascítica, entretanto, os machos são mais suscetíveis.

\section{Referências}

AMORIM FILHO, A.S. Aspectos econômicos da ascite em frangos de corte no Brasil. In: CONGRESSO BRASILEIRO DE AVICULTURA, 9., 1989, Brasília. Anais. Brasília: União Brasileira de Avicultura, 1989. p.111-120.

BACK, A. Ascite em frangos de corte: a situação na empresa avícola brasileira. In: CONFERÊNCIA APINCO DE CIÊNCIA E TECNOLOGIA AVÍCOLAS, 1991, Campinas. Anais. Campinas: Fundação Apinco de Ciência e Tecnologia Avícolas, 1991. p.101105.

BARBOSA, M.J.B. Efeitos de níveis de energia metabolizável e da forma física da ração sobre o desempenho de frangos de corte criados com separação de sexo. 1992. 86p. Dissertação (Mestrado) - Universidade Federal de Minas Gerais, Belo Horizonte.

BOTTJE, W.G.; ERF, G.F.; BERSI, T.K.; WANG, S.; BARNES, D.; BEERS, K.W. Effect of dietary dl- $\alpha$-tocopherol on tissue $\alpha$ - and $\gamma$-tocopherol and pulmonary hypertension syndrome (ascites) in broilers. Poultry Science, v.76, p.1506-1512, 1997.

CAMPOS, E.J.; COLL, M.A.C.; COLL, F.C.; COTA, J.T.B. Comparação entre rações fareladas, granuladas e extrusadas sobre o desempenho de frangos de corte criados com separação de sexo. In: CONGRESSO BRASILEIRO DE AVICULTURA, 3., 1979, Belo Horizonte. Anais. Belo Horizonte: União Brasileira de Avicultura, 1979. p.521-542.

CUEVA, S.; SILlAU, H.; VALENZUELA, A.; PLOOG, H. High altitude induced pulmonary hypertension and right heart failure in broiler chickens. Research in Veterinary Science, v.16, p.370374, 1974.

DALE, N.; VILLACRES, A. Relationship of two-week body weight to the incidence of ascites in broilers. Avian Diseases, v.32, p.556$560,1988$.

FURLAN, R.L. Efeitos do estresse hídrico, alimentar e térmico sobre parâmetros físicos e químicos do sangue de cinco linhagens comerciais de frangos de corte. 1992. 98p. Dissertação (Mestrado) - Universidade Estadual Paulista, Jaboticabal.

GEHLE, M.H.; POWELL, T.S.; ARENDS, L.G. Effect of different feeding regimes on performance of broiler chickens reared sexes separate or combined. Poultry Science, v.53, p.1543-1548, 1974.

GONZALES, E.; BUYSE, J.; TAKITA, S.; SARTORI, J.R.; DECUYPERE, E. Metabolic disturbances in male broilers of different strains: 1. Performance, mortality, and right ventricular hypertrophy. Poultry Science, v.77, p.1646-1653, 1998.

HARMS, R.H. Should male and female broilers be grown separately? Feedstuffs, v.41, p.52-53, 1969.
HULAN, H.W.; NASH, D.M.; CORNER, A.H.; PROUDFOOT, F.G. Some aspects of the composition of avian ascitic fluid. Poultry Science, v.63, p.1357-1363, 1984.

JULIAN, R.J.; FRIARS, G.W.; FRENCH, H.; QUINTON, M. The relationship of right ventricular hypertrophy, right ventricular failure, and ascites to weight gain in broiler and roaster chickens. Avian Diseases, v.31, p.130-135, 1987.

LOPEZ COELLO, C.; MENOCAL, J.A.; GONZALES, E.A.; PELAEZ, C.V. El sindrome ascitico en pollos de engorda. In: CONFERÊNCIA APINCO DE CIÊNCIA E TECNOLOGIA AVÍCOLAS, 1991, Campinas. Anais. Campinas: Fundação Apinco de Ciência e Tecnologia Avícolas, 1991. p.75-96.

LOPEZ COELLO, C.; WIDEMAN JUNIOR, R.F. Ascitis: un importante factor en la mortalidad de asaderos. Industria Avicola, v.33, p.12-17, 1986.

LOVATTO, Z.A. Desempenho de seis linhagens comerciais de matrizes de frangos de corte, criadas com pesos corporais diferentes durante a fase de recria. 1989. 139p. Dissertação (Mestrado) - Universidade Federal de Minas Gerais, Belo Horizonte.

MACARI, M.; GONZALES, E.; FURLAN, R.L. Doenças metabólicas em frangos de corte. Avicultura \& Suinocultura Industrial, v.80, p.18-20, 1991.

ORR, H.L.; HUNT, E.C.; RANDALL, C.J. Yield of carcass, parts, meat, skin and bone of eight strains of broilers. Poultry Science, v.63, p.2197-2200, 1984.

SANTOS, A.A. Níveis de energia e proteína em rações de acabamento para frangos de corte: efeitos sobre linhagens e sexo. 1977. 78p. Dissertação (Mestrado) - Universidade Federal de Minas Gerais, Belo Horizonte.

SCRIVNER, L.H. Experimental edema and ascites in poults. Journal of the American Veterinary Medical Association, v.108, p.2732, 1946.

SILVA, J.M.L. da. Ascite em frangos de corte: a situação no Brasil. In: CONFERÊNCIA APINCO DE CIÊNCIA E TECNOLOGIA AVÍCOLAS, 1991, Campinas. Anais. Campinas: Fundação Apinco de Ciência e Tecnologia Avícolas, 1991. p.97-100.

SILVA, J.M.L. da. Ascitis en pollos de engorde: un nuevo desafío. Avicultura Profesional, v.3, p.57-59, 1985.

SONCINI, R.A. Fatores predisponentes da síndrome de ascite em frangos de corte. In: CONGRESSO BRASILEIRO DE AVICULTURA, 11., 1989, Brasília. Anais. Brasília: União Brasileira de Avicultura, 1989. p.121-129.

TEUSCHER, E.; LOPEZ, E.V.; ALVAREZ, R. Pathologicalanatomical studies on an ascites syndrome in fattening chickens at high altitude. Zentralblatt fur Veterinarmedizin, v.18, p.380-394, 1971.

WIDEMAN JUNIOR, R.F. Patogenia da ascite em frango de corte o que sabemos? Ascite em aves. In: CONGRESSO BRASILEIRO DE AVICULTURA, 11., 1989, Brasília. Anais. Brasília: União Brasileira de Avicultura, 1989. p.99-100.

Recebido em 8 de julho de 2003 e aprovado em 18 de maio de 2004 